\title{
A UNIVERSIDADE, O MUSEU E A ESCOLA: O ENSINO DE HISTÓRIA E O VIÉS EXTENSIONISTA ${ }^{1}$
}

\section{THE UNIVERSITY, THE MUSEUM AND THE SCHOOL: THE TEACHING OF HISTORY BY EXTENSION BIAS}

\author{
Érika Oliveira Amorim² \\ Luciana do Carmo Narciso ${ }^{3}$ \\ Thaise Oliveira Paula ${ }^{4}$
}

\begin{abstract}
Resumo: Este artigo apresenta as especificidades do projeto de extensão "A universidade, a cidade e nós: memória e patrimônio nos caminhos de investigação", que foi desenvolvido pela Universidade do Estado de Minas Gerais (UEMG), na cidade de Carangola, entre os anos de 2014 e 2016. Envolveu graduandos dos cursos de História e Turismo, promovendo a interação entre espaço acadêmico, comunidade escolar e o Museu da cidade. As ações se dividiam em duas etapas: a primeira consistia no oferecimento de Oficinas Temáticas aos estudantes do nono ano do Ensino Fundamental da E.E. João Belo de Oliveira. Esses encontros visavam debates sobre Patrimônio Histórico e Cultural e eram organizados respeitando-se o calendário escolar da instituição de ensino. Na segunda etapa do projeto ocorria uma visita guiada ao Museu e Arquivo Histórico de Carangola. O projeto possibilitou pensar o Ensino de História a partir das relações que os indivíduos têm com os lugares de memória, ao mesmo tempo em que problematizava e difundia a visitação crítica e participativa ao museu, inserindo os graduandos da UEMG nos possíveis campos em que atuariam enquanto profissionais: a escola e o museu.
\end{abstract}

\footnotetext{
${ }^{1}$ Este trabalho contou com o apoio do Edital PAEx 01/2014.

${ }^{2}$ Docente no Curso de História da Universidade do Estado de Minas Gerais (UEMG), Unidade Carangola. Doutoranda em História Social das Relações Políticas pela Universidade Federal do Espírito Santo (UFES). Mestre em Extensão Rural pela Universidade Federal de Viçosa (UFV). Email: erikaoamorim@hotmail.com

${ }^{3}$ Licenciada em História pela Universidade do Estado de Minas Gerais (UEMG), Unidade Carangola.

Mestranda em Patrimônio Cultural, Paisagens e Cidadania pela Universidade Federal de Viçosa (UFV). E-mail: luciana.narciso@ufv.br

${ }^{4}$ Turismóloga graduada pela Universidade do Estado de Minas Gerais (UEMG), Unidade Carangola

Estudante do Curso de Geografia (licenciatura) na Universidade do Estado de Minas Gerais (UEMG), Unidade Carangola. E-mail: thaise.oliveira.paula@hotmail.com
} 
Palavras-chave: Patrimônio Histórico. Patrimônio Material. Museu. Ensino de História.

\begin{abstract}
This article presents the specificities of the extension project "The University, the City and Nodes: Memory and Heritage in the Research Paths", which was developed by the University of the State of Minas Gerais (UEMG), in the city of Carangola, between the 2014 and 2016. It involved undergraduates from the courses of History and Tourism, promoting the interaction between academic space, school community and the Museum of the city. The actions were divided into two stages: the first consisted of offering Thematic Workshops to the students of the ninth grade of Elementary School of E.E. João Belo de Oliveira. These meetings aimed at debates on Cultural and Historical Patrimony and were organized respecting the academic calendar of the educational institution. In the second stage of the project there was a guided visit to the Museum and Historical Archive of Carangola. The project made it possible to think about the Teaching History based on the relationships that individuals have with places of memory, while at the same time problematizing and disseminating critical and participative visitation to the museum, inserting UEMG undergraduates into the possible fields in which they would act as professionals: the school and the museum.
\end{abstract}

Keywords: Historical Patrimony. Material Patrimony. Museum. Teaching History.

\title{
Introdução
}

Desenvolver ações pautadas na tríade ensino-pesquisa-extensão era o alicerce do Projeto de Extensão desenvolvido na Universidade do Estado de Minas Gerais (UEMG), unidade Carangola, dentre os anos 2014 e 2016, tendo o Plano Nacional de Extensão Universitária (PNExt), como norteador das diretrizes da extensão universitária. Tomava-se a extensão como uma via de mão dupla, a qual possibilita a troca de saberes entre universidade e comunidade. Objetivava dinamizar o acesso de estudantes do ensino fundamental ao Museu e Arquivo Histórico de Carangola ${ }^{5}$, incentivando o conhecimento e a valorização do patrimônio histórico e cultural local. Ao

\footnotetext{
5 O Museu e Arquivo Histórico de Carangola foi criado em 1950 e instituído por meio da Lei Municipal $n^{\circ}$ de 14 de maio de 1959. Possui um vasto acervo de documentos históricos, fotografias, mobiliário, artes sacras, obras de arte produzidas por artistas locais, artefatos de tribos indígenas que viveram na região, bem como achados arqueológicos. Está sob a tutela da Secretaria Municipal de Cultura e, desde 2005, localizado em um antigo galpão construído em 1919, cedido em comodato pela Empresa Barbosa \& Marques à Prefeitura Municipal de Carangola por um período de 20 anos. Atualmente, o espaço físico é precário, apresentando problemas de infiltrações que comprometem o acervo.
}

História \& Ensino, Londrina, v. 25, n. 1, p. 373-389, jan./jun. 2019 
mesmo tempo, proporcionava a formação profissional aos discentes dos cursos de História e Turismo, pois promovia o contato direto com o acervo histórico e arquivístico, a experiência do ensino de História e a organização de visitas guiadas. O projeto envolvia esses discentes na elaboração de Oficinas Temáticas aos alunos da Rede Pública estadual. Esses encontros ocorriam no horário das aulas e contava com o apoio da equipe gestora da Instituição, que mediava o agendamento das oficinas com os professores da escola, a fim de não prejudicar o andamento das disciplinas e o cronograma dos docentes.

Durante a elaboração do projeto de extensão tratado neste texto, buscou-se valorizar o lugar de memória ${ }^{6}$ existente na cidade, já que Carangola se destaca pelo seu patrimônio histórico material e imaterial. Pensou-se, ainda, em transformar o espaço do Museu e Arquivo Histórico em local de pesquisa e prática extensionista, em parceria entre a Universidade do Estado de Minas Gerais (UEMG) e a Prefeitura Municipal, entidade pública responsável por mantê-lo. Tal parceria ainda não foi implementada, no entanto permanece como uma das possibilidades do Curso de História da UEMG, unidade Carangola.

Por se tratar de um projeto de Extensão, a relevância social se firmava na promoção do acesso da comunidade aos bens culturais e patrimoniais que a cidade oferece, valorizando os saberes dessa população no processo coletivo de construção do conhecimento. Os estudantes do nono ano do Ensino Fundamental da rede pública estadual, ao participar das oficinas temáticas e das visitas guiadas ao Museu, representavam multiplicadores de saberes sobre o patrimônio histórico-cultural local.

A extensão universitária permite a interligação entre a cultura científica e a cultura das humanidades, que é o papel dos museus, dos espaços expositivos, dos teatros, das galerias, das bibliotecas, dos arquivos, dos centros de documentação. Tais espaços são veículos indispensáveis de

\footnotetext{
${ }^{6}$ Expressão dada por Pierre Nora (1993).
} 
mediação entre os produtores de conhecimentos e bens simbólicos e os destinatários dessas ações, sejam eles estudantes ou sujeitos externos à universidade, igualmente legítimos destinatários da ação universitária (PAULA, 2013).

Metodologicamente, as ações do projeto de extensão se amparavam na exploração dos objetos culturais - fotografias de patrimônios materiais da cidade - em sala de aula e, ainda, no espaço institucional do museu.

As etapas metodológicas consistiam na observação, no registro, na exploração e na apropriação dos objetos. Ou seja, os estudantes desenvolviam ações voltadas para a identificação visual dos espaços apresentados nas fotografias, percepção visual e simbólica, interpretação de seus significados, análise crítica de seus usos e, por fim, a internalização e o envolvimento com a valorização do bem cultural. Essas etapas se desenvolviam no decorrer das Oficinas Temáticas e culminavam com a visitação ao museu, oportunidade na qual se explorava reflexões e observações dos espaços da cidade aproveitando-se o trajeto da escola ao museu e do museu para a escola.

\section{Ensino de História e Extensão Universitária}

A Extensão Universitária possui, em sua gênese, natureza interdisciplinar e educativa. Para além das acepções do termo "extensão" como atividade mecanicista que oferece algo a alguém, ou que substitui uma forma de conhecimento por outra (FREIRE, 2014), a atividade extensionista está alinhada ao processo de troca e construção de saberes coletivos.

Esse modelo de ação extensionista passou a ser difundido no Brasil a partir dos anos 1980, período no qual a extensão era chamada de "acadêmico institucional", quando as ideias e práticas de Paulo Freire passaram a fundamentar os conceitos e práticas da Extensão Universitária no país (AMORIM, 2017). 
Foi nesse sentido que o Projeto de Extensão de que trata este texto se desenvolveu e pautou sua agenda de ações, no período de abril de 2014 a dezembro de 2016. Levou em consideração que a atuação extensionista estabelece uma via simultânea entre universidade e comunidade na qual Ensino e Pesquisa são articulados de maneira indissociável.

Nessa dialogicidade, os estudantes que participaram do Projeto foram envolvidos em atividades que formavam uma rede de saberes que abarcava diferentes atores sociais no espaço escolar e na universidade.

No ambiente escolar, as ações envolviam a participação dos professores da Escola Estadual, os quais cediam suas aulas para que as oficinas do Projeto pudessem ser realizadas. Alguns deles aproveitavam a oportunidade para exercer a prática interdisciplinar, buscando unir os temas abordados nas Oficinas às aulas de suas disciplinas. Um bom exemplo foi o da Professora de Língua Portuguesa, que elaborou uma Oficina de Produção de Textos com base na visitação ao Museu, promovida pelo Projeto. Esse diálogo interdisciplinar faz com que

[...] duas ou mais disciplinas interajam entre si, esta interação podendo ir da simples comunicação das ideias até a interação mútua dos conceitos, da epistemologia, da terminologia, da metodologia, dos procedimentos, dos dados e da organização da pesquisa (TEIXEIRA, 2007, p. 69).

Nesse sentido, a abordagem interdisciplinar do Projeto foi além do que se esperava já que objetivava, inicialmente, propor o diálogo entre a formação do professor de História e do Turismólogo. Assim, a interdisciplinaridade, que se caracteriza por operacionalizar recursos de duas ou mais disciplinas, permitiu a intensidade das trocas entre os especialistas e uma integração real das disciplinas no interior de um mesmo projeto de pesquisa (JAPIASSÚ, 1976, p. 74).

No ambiente acadêmico, a equipe se reunia para debater leituras com enfoque no conceito de "patrimônio", enquanto categoria de pensamento importante para a vida social e mental de qualquer coletividade humana 
(GONÇALVES, 2003, p. 22). Aproximou-se, também, da recente abordagem do patrimônio intangível, oposta ao chamado "patrimônio de pedra e cal", concepção que visa a aspectos da vida social e cultural, dificilmente abrangidos pelas concepções mais tradicionais (GONÇALVES, 2003, p. 24).

Após o estudo dos textos, o grupo se reunia para organizar Oficinas Temáticas que seriam oferecidas aos estudantes do nono ano do Ensino Fundamental, da Rede Pública Estadual. Esses encontros versavam sobre temas como "Patrimônio e Memória" e "Fotografias da Cidade". Alguns dos produtos das Oficinas são demonstrados a seguir.

\section{Oficinas temáticas: a sala de aula como limiar para experiências docentes}

Antes das visitas guiadas ao Museu e Arquivo Histórico de Carangola, os estudantes da rede pública estadual participaram das Oficinas, momento de interação entre a equipe do Projeto e o ambiente escolar, propriamente, a sala de aula. Para os alunos dos cursos de graduação em História e Turismo, a vivência na escola possibilitava experiências nos futuros campos de atuação profissional:

Os estudantes dos cursos de graduação desenvolvem habilidades no que se refere a preparação de aulas, que se materializam por meio das oficinas, e assim promovem a sensibilização dos alunos para participarem da visita orientada ao Museu (AMORIM, 2017, p. 174 ).

Durante a organização das Oficinas a professora coordenadora do Projeto se reunia com os graduandos dos cursos de História e Turismo, ocasião em que eram debatidas as ações que seriam realizadas nos encontros e os estudantes se preparavam para as primeiras experiências na docência. 0 grupo escolhia temas relacionados ao Patrimônio Histórico e Cultural que seriam propostos nas Oficinas e definia a forma de abordagem. 
A primeira Oficina recebeu o nome de "Patrimônio e Memória" e o debate girou em torno da legislação brasileira que privilegia os bens edificados em detrimento da recente qualificação de "patrimônio intangível", considerada terminologia mais apropriada, pois remete ao transitório, fugaz, que não se materializa em produtos duráveis (FONSECA, 2003, p. 66).

Dessa maneira, o encontro apresentou aos estudantes os bens materiais da cidade, os quais foram registrados como patrimônios históricos municipais por iniciativa do Conselho Deliberativo Municipal do Patrimônio Cultural de Carangola. Esse encontro objetivava ainda analisar a memória dos estudantes com relação aos Patrimônios Históricos Materiais locais.

Foram apresentadas fotografias de quatro Patrimônios tangíveis considerados de maior visibilidade, dada a localização em pontos centrais do município. São eles: a Praça Cel. Maximiano; o Prédio do Fórum da Comarca de Carangola; a Estação Rodoviária Wigdston Mendes de Souza e o Prédio Principal da Universidade do Estado de Minas Gerais (UEMG). Essa oficina foi a que gerou resultados e produtos mais curiosos.

No decorrer da apresentação dos conceitos de "Patrimônio" e "Memória", demonstrou-se aos alunos como cada uma dessas categorias se relaciona à comunidade em que estão inseridos. Enfocou-se que o espaço da cidade e a experiência que guardamos em cada um de nós - os símbolos e emblemas vão sendo forjados com a passagem do tempo, bem como nossos sentimentos de pertencimento e identidade (MIRANDA e SIMAN, 2013, p. 15).

Após a explanação dos conceitos e discussão do tema, propôs-se a atividade de produção de cartazes por meio de colagens e/ou desenhos que representassem a relação que os alunos tinham com aqueles patrimônios materiais apresentados. Para a surpresa da equipe, os cartazes que foram sendo elaborados, em sua maioria, não mencionavam nenhuma relação de proximidade com os patrimônios edificados da cidade, mas, sim, com fatos pessoais e símbolos relacionados à experiência pessoal de cada um. Percebeuse que os estudantes incorporaram mais a noção de memória no sentido 
afetivo do que propriamente relacionada aos bens materiais e espaços da cidade.

Figura 1: Produtos da Oficina "Patrimônio" e "Memória"

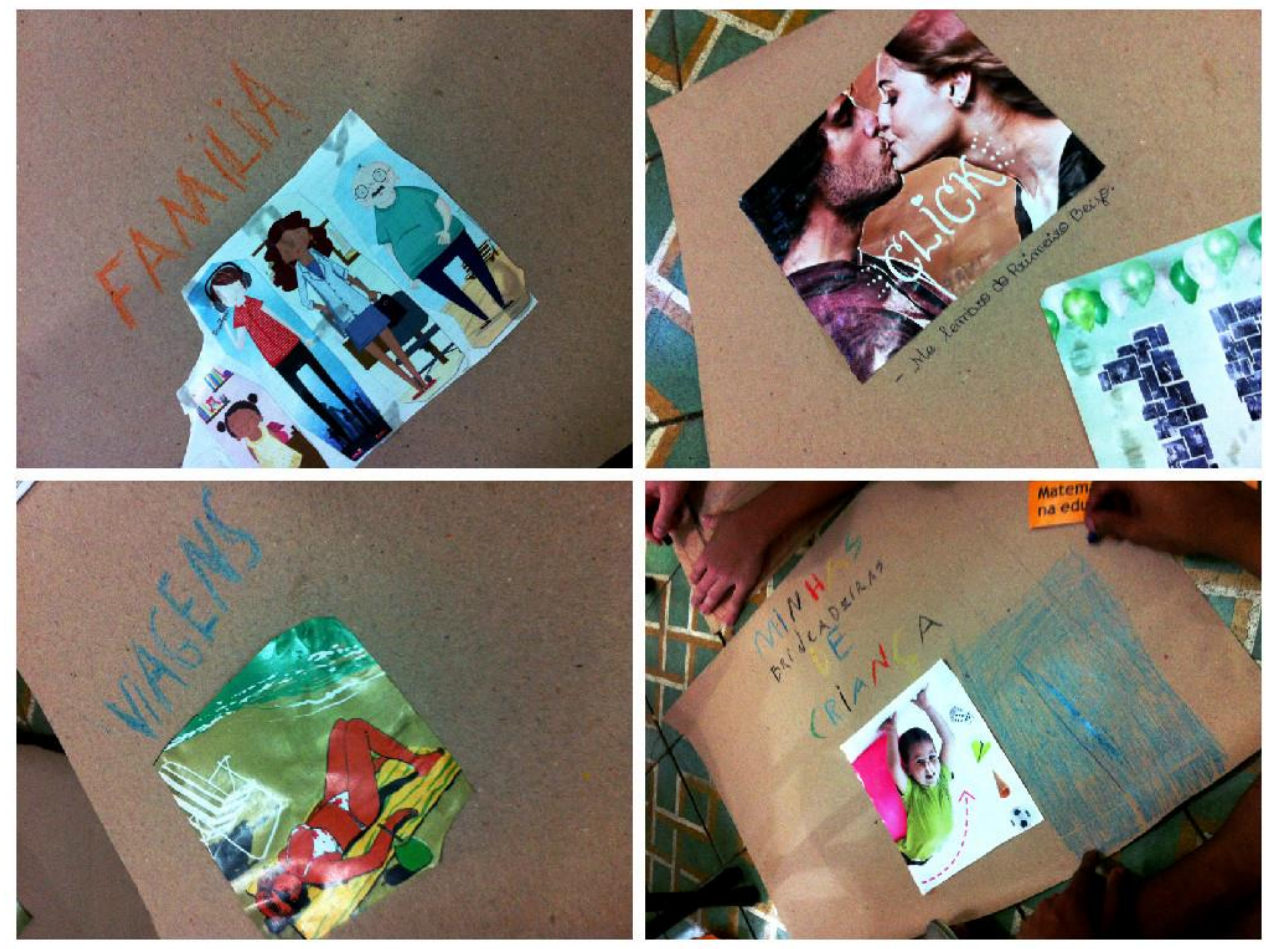

Fonte: Dados da pesquisa, agosto/2014.

A montagem acima, com quatro cartazes produzidos pelos estudantes, apresenta a percepção deles no que se referia a relação entre "patrimônio" e "memória". As produções, destacadas na Figura 1, demonstram que os alunos evidenciaram representações de famílias e pessoais, como o primeiro beijo, viagens e brincadeiras de criança.

Nota-se que os aspectos pessoais foram relatados no sentido de uma memória afetiva. Portelli (2016) disserta que a memória não é um mero depósito de informações, mas um processo contínuo de elaboração e reconstrução de significados. Para esses alunos, o sentido de memória estava relacionado às suas famílias, consideradas por eles como patrimônio. Há que se destacar que aprendemos a usar a palavra "patrimônio" atribuída ao sentido 
de propriedade ou na acepção econômica de um país, de uma família ou, também, no sentido de "colecionamento" (GONÇALVES, 2003). Está, ainda, relacionada ao sentido de proteção. Quando requeremos inventariar manifestações culturais, saberes ou falares, não estamos buscando preservar os registros de tais práticas?

Após a realização dessa Oficina, a equipe do projeto discutiu tal relação e questionou: estariam esses alunos e alunas buscando algum tipo de preservação das memórias de suas famílias?

Imbuídos dessa análise organizou-se o próximo encontro, realizado no mês seguinte. Nesse momento, já se via os alunos da Escola Estadual sob outra perspectiva e pensou-se numa abordagem introspectiva e na relação desses alunos, e suas famílias, com os patrimônios materiais da cidade.

Dessa maneira, propôs-se a Oficina "Fotografias da Cidade", na qual os estudantes deveriam organizar uma Linha do tempo com fotografias dos patrimônios materiais apresentados, os quais estavam registrados em fotos de diferentes momentos e períodos, a fim de despertar nos estudantes a noção de alteração das características inicias de cada bem.

Na Figura 2, pode-se identificar a produção dos alunos na Oficina em que realizaram duas linhas do tempo: uma sobre a Praça Coronel Maximiano e a outra sobre o Pontilhão de Ferro. O objetivo do encontro era demonstrar que esses testemunhos materiais são valorizados como expressões culturais de suas épocas, com reflexões no que se refere à ocupação deles nos espaços da cidade. 
Figura 2: Produtos da Oficina "Fotografias da Cidade"
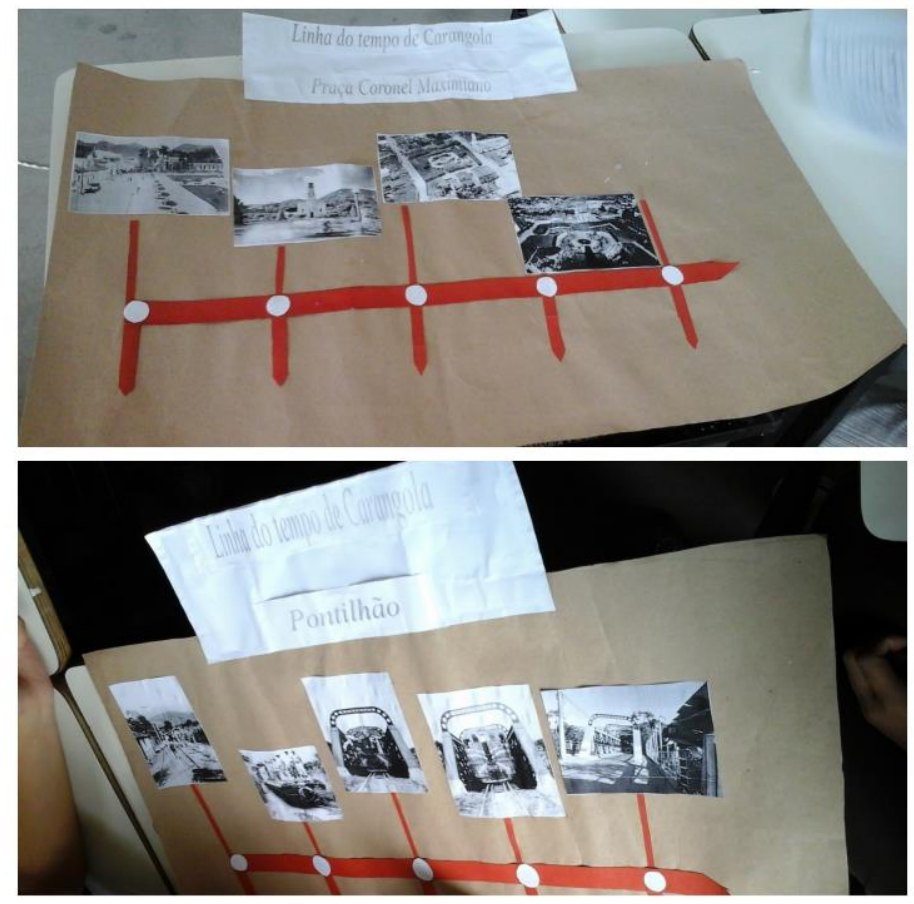

Fonte: Dados da pesquisa, agosto/2014.

Essa Oficina permitiu que os estudantes associassem suas memórias a esses espaços da cidade, no mesmo sentido de "lugares de memória" de Pierre Nora (1993). O suporte para esse tipo de associação baseou-se nas recordações dos alunos de momentos nos quais vivenciaram experiências em tais espaços, em companhia da família. Alguns relataram lembranças do "Pontilhão de Ferro" por passarem por ele quando visitaram parentes residentes na região vizinha. Outros destacaram o chafariz da Praça e diferentes momentos do ano em que ele não funcionava, com ênfase para o período natalino, no qual costumava ser tampado por um tablado para abrir a "Casa do Papai Noel".

As reflexões oriundas dessa Oficina permitiram-nos compreender o sentido dado por Lefebvre (2016) do direito à cidade em sua pluralidade, possibilitando olhares diversos para os espaços urbanos e diferentes 
problematizações com uso da memória. Nesse sentido, os encontros entre universidade e escola conceberam

A interpelação dos sentidos e consciência histórica que pode ser ativada a partir da experiência com a pluralidade urbana [que] afeta, potencialmente, os alunos e professores e, desse modo, pode vir a ser mobilizada em ações de formação e reflexividade docentes (MIRANDA e BLANCH, 2013, p.66).

Assim, a experiência de formação profissional possibilitada pelo projeto aliou-se ao despertar dos graduandos para conceber a cidade como vetor das relações sociais. Ademais, o enfoque da temática do Patrimônio Histórico e Cultural se tornou fio condutor para novas análises sobre os espaços da cidade, cujos significados são atribuídos de maneiras diferentes por cada indivíduo.

\section{Universidade, Escola e Museu: espaços de construção coletiva de saberes}

As etapas do projeto se dividiram em três espaços institucionais: a universidade, a escola e o museu. Nesses locais foram discutidas noções conceituais de Patrimônio e os diferentes tipos de memórias, ultrapassando os limites de patrimônio arquitetônico, passando do material e visível para o invisível e simbólico, ampliando o que deve ser objeto de preservação e memória (SIMAN e COSTA, 2013).

O momento da visitação ao museu somente ocorreu após a realização das duas Oficinas, pois além da preparação dos estudantes para a visita guiada, era necessário criar uma relação de confiança e diálogo entre a equipe e os alunos da Escola Estadual. Esse processo de construção de relações foi fundamental, já que era necessário haver interação entre os estudantes e os jovens universitários, futuros Turismólogos e professores de História. 
Em trabalho anterior foi destacado que aproximar o aluno de espaços culturais como o museu é explorar diferentes linguagens e ferramentas de aprendizagem. Estimular o jovem estudante de licenciatura em História ao contato com essa potencial ferramenta de trabalho também é desafiador (AMORIM, 2017). Isso porque para o jovem professor não é tarefa fácil colocar em prática a experiência de viabilizar uma visita a espaços educativos para além dos muros da escola.

As potencialidades do ensino de História por meio da vivência em espaços museológicos são notórias. Contudo, como colocálas em prática? Como mostrar ao jovem que se prepara para ser professor que levar seus alunos ao museu não significa trazer para si uma grande preocupação? (AMORIM, 2017, p. 182).

A experiência dos encontros desses jovens graduandos com os alunos durante as Oficinas possuía o intuito de levá-los a crer que as possibilidades pedagógicas são múltiplas, mas requerem planejamento de ações, principalmente no que se refere aos objetivos que se pretendem alcançar.

Além das abordagens teóricas das oficinas, a interação entre a equipe do Projeto e os estudantes permitiu a construção de uma relação de confiança mútua, já que outro tipo de aprendizagem seria explorado, e em outro espaço: o museu. Assim, buscou-se evitar que 0 ato da visita fosse pautado na "Pedagogia do não", expressão dada por Siman (2003): não correr, não brincar, não conversar com os colegas.

A autora reflete sobre a relação entre escola e museu e problematiza que ambos espaços possuem suas especificidades e aproximações e que, atualmente, passam por transformações no que se refere aos papéis de formação dos sujeitos sociais:

[...] no atual momento, podemos dizer que tanto a cultura escolar, quanto a cultura museológica encontram-se em processo de transformação. Novas práticas baseadas em novas concepções do que seja o ato de ensinar e aprender e o ato de preservar e comunicar vem contribuindo para a redefinição do papel de ambas as instituições (SIMAN, 2003, p. 190). 
Essas novas práticas mencionadas por Siman, refletem na desconstrução do caráter meramente contemplativo das visitações aos museus. Durante as ações do projeto de extensão e, especificamente, no que se refere a visitação ao espaço do museu, buscou-se estimular o contato dos estudantes com o acervo exposto no intuito de despertar o reconhecimento de si naquele contexto da comunidade em que estão inseridos. Isso porque a visita levou em conta a crítica apontada por Siman (2003) de que, tradicionalmente, a escola interage com o museu orientando o aluno a exercer relação de reverência e distanciamento com o acervo, limitando-se a uma atitude de passividade e contemplação em relação à História.

Nesse sentido, a prática pedagógica realizada no espaço do museu despertou a interação dos alunos diante dos objetos em exposição, levando-se em conta que:

[...] os objetos da cultural material, simbólica e estética presentes nos museus além de serem alvo de admiração deveriam contribuir para a compreensão das muitas faces das experiências sociais e históricas dos sujeitos. Esses objetos seriam, assim, mediadores na construção do conhecimento histórico, na medida em que os alunos ao interagirem com os mesmos possam, à partir de suas mais diferentes reações - de espanto, de curiosidade, de rememoração, de emoção - ser convidados interpretá-los em articulação com outros tempos de sua história, de seu grupo social, da História da Cidade, do País (SIMAN, 2003, p. 191).

O processo de visita ao museu alcançou a dimensão sensível da observação reflexiva, explorando as percepções dos visitantes perante o que aquele espaço despertava. O intercâmbio entre o grupo de estudantes e equipe do projeto de extensão permitiu a construção de saberes que fugia a contemplação passiva dos objetos ali existentes. Buscou-se, ainda, preterir a ideia de uma História mumificada para uma História multiplicada (PEREIRA e SIMAN, 2009). 
Desse modo, o saber coletivo abarcou múltiplas experiências que envolveram desde a formação profissional de professores de História e Turismólogos até a ressignificação do sentido de uma visita ao museu, tanto para os alunos quanto para os graduandos que participaram do projeto de extensão, potencializando o valor histórico do patrimônio e da memória coletiva.

\section{Algumas reflexões}

A ação do professor de História no espaço do museu não se limita ao discurso teórico sobre o conhecimento do passado, mas, sim, à articulação entre os registros históricos e a formação da identidade da comunidade a qual se destina, promovendo a reflexão sobre as experiências dos sujeitos.

Pierre Nora (1993), ao discorrer sobre a criação dos lugares de memória - museus, arquivos, cemitérios - assegura que esses espaços nascem e vivem do sentimento de que não há memória espontânea e, por isso, esses locais devem ser criados. Pontua, ainda, que os lugares de memória vivem de sua aptidão para a metamorfose, no incessante ressaltar de seus significados e no silvado imprevisível de suas ramificações (NORA, 1993, p. 22).

Nesse sentido, explorando as possibilidades dos espaços de memória e do ambiente escolar, pode-se afirmar que o patrimônio histórico se constitui ferramenta de formação de sujeitos.

No que se refere à atividade extensionista apresentada neste texto, destaca-se seu pioneirismo e sua abordagem interdisciplinar ao envolver discentes dos cursos de História e Turismo da UEMG.

Durante os três anos em que o projeto atuou ampliou-se o diálogo entre a Universidade e a Escola, associados à tríade da ação universitária EnsinoPesquisa-Extensão. No ambiente acadêmico, contou com a participação de seis graduandos desses dois cursos, seja como alunos bolsistas, seja como alunos

História \& Ensino, Londrina, v. 25, n. 1, p. 373-389, jan./jun. 2019 
voluntários. No âmbito escolar, três turmas de nono ano do Ensino Fundamental, da Escola Estadual João Belo de Oliveira, participaram ativamente das ações, com amplo envolvimento da equipe gestora e seu corpo docente.

O intercâmbio entre as duas formações acadêmicas - História e Turismo procurou construir aprendizagens por meio do encontro entre mediadores culturais e simbólicos existentes no museu e os sujeitos que os acessaram por meio da visitação e o contato com o cotidiano escolar, sobretudo a sala de aula.

Desse modo, o museu, enquanto lugar de memória, se fez espaço de ressignificação do passado pelos visitantes e constitui-se em mais um espaço de formação profissional e de diálogo da comunidade acadêmica com sociedade.

\section{Referências}

AMORIM, Érika Oliveira. Ensino de História: como a extensão universitária potencializa a formação profissional. Revista História Hoje, v. 6, n. 11, p. 172190, 2017.

FONSECA, Maria Cecília Londres. Para além da pedra e cal: por uma concepção ampla de patrimônio cultural. In: ABREU, Regina. CHAGAS, Mário (Orgs).

Memória e Patrimônio: ensaios contemporâneos. Rio de Janeiro: DP \&A, 2003. P. 56-76.

FREIRE, Paulo. Extensão ou Comunicação. 13a edição. São Paulo: Paz e Terra. 2014.

GONÇALVES, José Reginaldo Santos. O Patrimônio como categoria de pensamento. In: ABREU, Regina; CHAGAS, Mário (Orgs.). Memória e Patrimônio: ensaios contemporâneos. Rio de Janeiro: DP \&A, 2003. P. 21-29. 
JAPIASSU, Hilton. Interdisciplinaridade e patologia do saber. Rio de Janeiro, Imago, 1976.

LEFEBVRE, Henri. O direito à cidade. São Paulo: Nebli, 2016.

MIRANDA, Sonia Regina; SIMAN, Lana Mara Castro. A cidade como espaço limiar: sobre a experiência urbana e sua condição educativa, em caminhos de investigação. In: . Cidade, Memória e Educação. Juiz de Fora: Editora UFJF, 2013.

MIRANDA, Sonia Regina; BLANCH, Joan Pagès. Cidade, Memória e Educação: conceitos para provocar sentidos no vivido. In: MIRANDA, Sonia Regina; SIMAN, Lana Mara Castro (Orgs.). Cidade, Memória e Educação. Juiz de Fora: Editora UFJF, 2013. P. 60-92

NORA, Pierre. Entre memória e história: a problemática dos lugares. Projeto História: Revista do Programa de Estudos Pós-graduados de História do Departamento de História da PUC-SP, v. 10, 1993.

PAULA, João Antônio de. A extensão universitária: história, conceito e propostas. Interfaces, Belo Horizonte, v.1, n.1, p.5-23, jul./nov. 2013. Disponível em: https:// www.ufmg.br/proex/revistainterfaces/index.php/IREXT/article/view/5/pdf; Acesso em: 11 ago. 2016

PEREIRA, Júnia Sales; SIMAN, Lana Mara de Castro. Andarilhagens em Chão de Ladrilhos. In.: FONSECA, Selva Guimarães (Org.). Ensinar e Aprender história: formação, saberes e práticas educativas. Campinas, SP: Editora Alínea, 2009. p. 277-295.

PORTELLI, Alessandro. História Oral como arte da escuta. Tradução Ricardo Santhiago. São Paulo: Letra e Voz, 2016.

SIMAN, Lana Mara de Castro. Práticas culturais e práticas escolares: aproximações a especificidades no ensino de História. História \& Ensino: Revista do Laboratório de Ensino de História, Londrina, v.9, p. 185-203, out. 2003. 
SIMAN, Lana Mara de Castro; COSTA, Janice Pereira da. Escola, museu e ensino de história: Perspectiva teórica e metodológica para avaliação desta relação: Um estudo de caso. Fóruns Contemporâneos de Ensino de História no Brasil on-line, v. 1, n. 1, 2013.

TEIXEIRA, E. F. B. Emergência da inter e da transdisciplinaridade na universidade. In: AUDY, J. L. N.; MOROSINI, M. C. (Org.). Inovação e interdisciplinaridade na universidade. Porto Alegre: EDIPUCRS, 2007. p. 58-80.

Recebido em 04 de junho de 2015 Aprovado em 14 de maio de 2018 